\title{
Childbearing preferences and family issues in Europe: evidence from the Eurobarometer 2006 survey
}

\author{
Maria Rita Testa*
}

\begin{abstract}
This article provides an overview of major findings described in the report on "Childbearing Preferences and Family Issues in Europe" written at the request of the European Commission, Directorate-General Communication, Opinion Polls (Testa 2006). The report confirms the emergence of below-replacement family size ideals in Europe: Austrian women aged 25-39 show indeed a mean value of 1.7 children. As expected, ideals are higher than actual or intended fertility, and when we add up the number of children already born with those people still intend to have in the future, several other countries show an average ultimately intended family size of less than two children. The presence of a supportive partner is the most important circumstance in childbearing decisions, and consistently, the lack of the right partner for raising children is the most frequent reason given for not meeting the fertility desires formulated at the beginning of the reproductive career. The contribution of both partners is considered necessary for a good family life, but the role of mothers is judged to be the more crucial one. Countries more liberal in terms of gender roles in family life also show preferences for larger families.
\end{abstract}

\section{Introduction}

The paper contains some major findings described in the report on "Childbearing Preferences and Family Issues in Europe" (Testa 2006). This extensive report analyses the questions on fertility issues included in the special Eurobarometer N. 253, wave 65.1 and $65.3^{1}$, carried out in 2006 by TNS Opinion \& Social, at the

* Maria Rita Testa, Vienna Institute of Demography, Austrian Academy of Sciences, Wohllebengasse $12-14,6^{\text {th }}$ floor, 1040 Vienna, Austria. Email: maria.rita.testa@oeaw.ac.at

1 The fieldwork was conducted in two stages: in February-March 2006 in the 25 Member States and in May-June 2006 in the acceding and candidate countries. I only concentrate on the EU-25, because the sample weights for the EU-29 were not available. For coherence I do not show results related to these countries in the cross-national analyses either. 
request of the European Commission, Directorate-General Communication, Opinion Polls. In that report I analyse each of the 18 questions related to childbearing preferences and attitudes included in the Eurobarometer (EB) questionnaire by gender and age, both at EU level and at the country level. In my paper I select only some questions which are examined at the EU-25 level, while cross-national comparisons based on women in reproductive ages complement the analysis and give support to the main findings.

First, I examine personal ideal family sizes, comparing the average values shown in the EB 2001 with those evidenced by EB 2006. I complement this part by looking at the relationship between the ideal quantum and the ideal timing of fertility. Second, I concentrate on ultimately expected family size which is a much stronger predictor of actual fertility behaviour. Third, I analyse the main relevant circumstances in childbearing decisions as well as the main perceived obstacles to complete fulfilment of individuals' fertility desires. The study of prevalent opinions on gender roles in family life is developed in order to see whether it has an impact on fertility preferences. Particular attention will be devoted to Austria, a country that has been constantly showing a preference for family sizes at belowreplacement level, whatever indicator is used to capture such a preference.

The EU-25 averages are weighted according to the population of each country, therefore these figures do not correspond to averages based on adding up the individual country figures. In addition, for each country we apply individual weights that are inverse to the probability of being included in the sample.

\section{On the Austrian below-replacement family size ideals}

In the Eurobarometer 2006 survey, two questions on ideal family size were asked to the respondents: one on the general ideal family size and another on the number of children people consider as ideal for their own personal family. Here I analyse only the second one which better reflects the respondents' own attitudes. Figure 1 shows the mean personal ideal family size by age and gender at the EU-25 level (last graph in the right panel), as well as for the EU-15 and the 10 new Member States separately. At the aggregate level, for either EU-25, EU-15 or NMS-10, there are no relevant differences in average values shown by males and females, but there is an increasing trend of ideals by age that takes a U-shape in the case of men, with the lowest ideals observed for males aged 25 to 39 (Fig. 1). The country results - which in many cases show the same age pattern observed at the EU level - have to be read with caution due to the small size of the national samples. $^{2}$

The analysis suggests that below-replacement family size ideals are prevailing among Austrian young women who show an average ideal family size of 1.69

Detailed information on the national sample sizes and on the exact number of respondents by gender and age group may be found in Testa, 2006. 
children. This is consistent with the evidence provided in earlier studies based on a previous round of the EB (Goldstein et al. 2003; Testa and Grilli 2006). This literature documented, for the first time, a substantial decline of fertility ideals in the young generations of German and Austrian women aged 20 to 34 years. ${ }^{3}$

\section{Figure 1:}

Mean personal ideal number of children by sex and age. Selected European countries and EU-25, EU-15 and the NMS-10
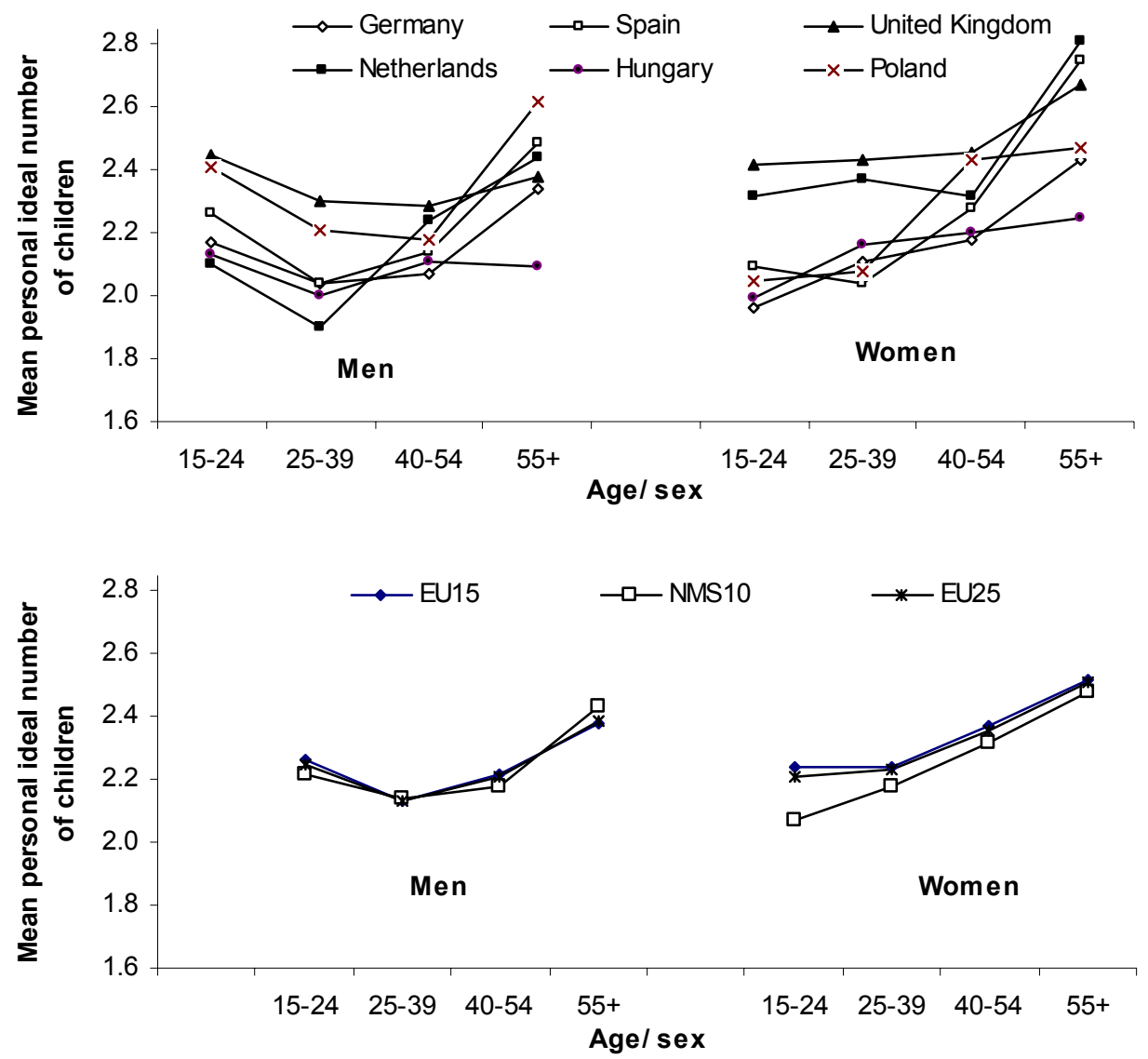

\footnotetext{
Note that these results would also be achieved without breaking down the respondents by age groups: Austrian men prefer, on average, 1.66 children, while Austrian women indicate, on average, a preference of 1.82 children. Both these values are below replacement.
} 
Two relevant questions are raised from this empirical evidence: first, is the culture of low fertility prevalent in Austria? Second, will this Austrian trait be spreading to the whole of Europe in the years to come? The answer to the second question might be beyond the scope of this paper, but knowing more on the Austrian case could help to shed light on the possible further diffusion of a lowfertility culture in the rest of Europe.

According to the EB 2006 data, Austria shows not only the lowest general and ideal family sizes - 1.6 and 1.7 children, respectively, among women aged 25 to 39 years - but also the lowest desired and intended family sizes. The desired number of children at age 20 is 1.5 , on average, among the female generations aged 25 to 39 . The ultimately expected number of children, i.e., the sum of children already born plus those planned for the future, is only slightly higher than those 1.5 children, with one child already born on average, and 0.5 children being planned for the future (Table 1). In previous studies we argued that young Austrians have lower ideals because they are more accustomed to small families, Austria is one of the first countries where total fertility went below replacement levels and consequently many people who are currently in the reproductive ages have been socialised in small families (Goldstein et al. 2003). We provide empirical justification for this by pointing out the existence of a significant intergenerational effect in the transmission of fertility ideals that occurs in a micro-macro framework: in regions where the parents' generations have had a lower number of children, young individuals today express a personal preference for smaller families as well (Testa and Grilli 2006).

Table 1:

Family size and childlessness indicators. Austria and EU-25. Women aged 25-39

\begin{tabular}{lccccc}
\hline Mean number of children & Austria (a) & EU-25 (b) & MIN & MAX & Diff. (a-b) * \\
\hline General ideal & 1.63 & 2.23 & 1.63 & 2.91 & -0.60 \\
Personal ideal & 1.69 & 2.23 & 1.69 & 2.84 & -0.54 \\
Desired at age 20 & 1.50 & 2.10 & 1.50 & 2.89 & -0.60 \\
Ultimately intended & 1.54 & 2.07 & 1.54 & 2.72 & -0.53 \\
Actual & 0.97 & 1.34 & 0.75 & 1.84 & -0.37 \\
\hline Childlessness (\%) & & & & & \\
Actual & 37 & 31 & 15 & 56 & 6 \\
Intended & 48 & 18 & 5 & 48 & 30 \\
\hline
\end{tabular}

Note: All the differences are significant at the $5 \%$ level.

From an empirical point of view, the 2001 EB survey suggested that the record-low fertility preferences of Austrian young women were driven by a higher proportion of respondents preferring small families, i.e, no child at all or just one, and a lower percentage of respondents preferring large families, i.e, three or more children, while the two-child norm is as common in Austria as in the other European countries (Goldstein, Lutz and Testa 2003). 
This result is confirmed by the new EB round carried out in 2006 (see Testa 2006), which also shows that below-replacement family size ideals are not just a temporary phenomenon but instead a more consolidated and durable preference.

This consideration is supplemented by three different pieces of information based on the 2006 EB data. First, Austria has the highest proportion of women in reproductive ages indicating an ideal of "no-child family": 11\% against 4\% observed in the EU-25 as a whole, and what's more, the change across ages in the preference from high to low family sizes is also most pronounced in Austria: the proportion of no-child has doubled among the youngest respondents aged 15-39 years, from 5 to $10 \%$. Second, Austria is one of the countries with the lowest proportion of young respondents already having one child who state that they feel pressure on behalf of their parents to having a second child: $18 \%$ versus $27 \%$ in the EU-25. Third, in Austria there is the highest share of female childless respondents who do intend to remain childless: around 48\% of women aged 25-39 without children do not express any fertility plans for the future, while the same proportion is $18 \%$ in the EU-25 (Table 1). Finally, actual childlessness is quite widespread in Austria: 37\% of Austrian women aged 25-39 years do not have any children, similar or greater values are registered only in Greece (40\%), Italy $(56 \%)$ and Denmark (42\%), while the average for the EU-25 is 31\% (Table 1).

The implications of the emergence of below-replacement family size ideals are clear and self-evident if we interpret such ideals as an upper bound for the realised fertility: ideals usually exceed actual fertility whereas it is very unlikely that realised childbearing surpasses the personal ideals.

\section{Declining ideal family sizes over the 2001-2006 period?}

The earlier literature on below-replacement family size ideals could not sort out temporal changes from life course adjustments and thus the interpretation of the low ideals of those young generations was left to the readers (Goldstein et al. 2003). Since the question on personal ideal family size has been repeated in the Eurobarometer survey 2006 by using exactly the same wording as in the 2001 round, it is now possible to make a distinction between these two dimensions, taking into account the limits imposed by the short temporal frame of five years, that is the inter-survey period. Table 2 reports the differences across ages, by confronting women of the same age group, 25-39, in 2001 and 2006, and the differences across cohorts, by comparing the average values of women aged 2539 in 2001 with those of women 5 years older in 2006. The comparison is made only for the EU-15 countries, which were covered in both Eurobarometer waves. Table 2 shows no substantial differences between the ideals reported in the two EB rounds. In the Austrian case, they tend to decline for women across ages, while remaining stable for women in the same birth cohorts, evidence that would be more in favour of a temporal change. 
Table 2:

Change of mean personal ideal family size by country. Women aged 25 to 39, EU-15. Eurobarometer 2001 and 2006

\begin{tabular}{lcccccc}
\hline & \multicolumn{2}{c}{ Cohorts $\mathbf{1 9 6 2 - 7 6}$} & Diff. & \multicolumn{2}{c}{ Age 25-39 } & Diff. \\
Countries & 2001 & 2006 & $2006-2001$ & 2001 & 2006 & $2006-2001$ \\
\hline & & & & & & \\
Austria & 1.75 & 1.75 & 0.00 & 1.75 & 1.69 & -0.06 \\
Belgium & 2.25 & 2.25 & 0.00 & 2.25 & 2.23 & -0.02 \\
Denmark & 2.43 & 2.63 & 0.20 & 2.43 & 2.50 & 0.07 \\
Finland & 2.49 & 2.50 & 0.01 & 2.49 & 2.61 & 0.12 \\
France & 2.51 & 2.66 & 0.15 & 2.51 & 2.48 & -0.03 \\
Germany & 1.73 & 2.13 & 0.40 & 1.73 & 2.11 & 0.38 \\
Germany East & 1.74 & 2.23 & 0.49 & 1.74 & 2.08 & 0.34 \\
Germany West & 1.73 & 2.12 & 0.39 & 1.73 & 2.12 & 0.39 \\
Greece & 2.36 & 2.42 & 0.06 & 2.36 & 2.31 & -0.05 \\
Ireland & 2.65 & 2.80 & 0.15 & 2.65 & 2.78 & 0.13 \\
Italy & 2.11 & 1.99 & -0.12 & 2.11 & 2.02 & -0.09 \\
Luxembourg & 2.27 & 2.28 & 0.01 & 2.27 & 2.14 & -0.13 \\
Netherlands & 2.08 & 2.32 & 0.24 & 2.08 & 2.37 & 0.29 \\
Portugal & 2.10 & 2.32 & 0.22 & 2.10 & 2.23 & 0.13 \\
Spain & 2.21 & 2.16 & -0.05 & 2.21 & 2.04 & -0.17 \\
Sweden & 2.52 & 2.53 & 0.01 & 2.52 & 2.59 & 0.07 \\
United Kingdom & 2.43 & 2.42 & -0.01 & 2.43 & 2.43 & 0.00 \\
EU-15 & 2.16 & 2.29 & 0.13 & 2.16 & 2.24 & 0.08 \\
\hline
\end{tabular}

Source: Testa (2002 and 2006)

Looking at the other countries, the ideals are stable or tend to increase, either across cohorts or ages. Half of the 15 EU countries experienced a temporal increase in the ideals between the two rounds. The new setting of the questionnaire's ${ }^{4}$ items may be partly responsible for this increase. Other than in the 2001 survey, the section of fertility and family issues is opened by a contextual question that ask respondents to indicate the solutions to the possible shortage in the work force. This preliminary question may have induced individuals to reflect about the future relevance of children for society, and consequently, to be more positive towards childbearing and large families.

In Germany, however, other reasons should be found to justify such an increase of family size ideals because here the boost is huge and also statistically significant at the 5\% level - unlike any other EU-15 country. This unexpected

4 The section of the EB 2006 questionnaire related to fertility items may be found in: Testa, 2006 (available at: http://www.oeaw.ac.at/vid/download/ReportESEMPLAgeingandFertility20061027.pdf). 
result may well be connected with some important change driven by the recent heated debate on childbearing attitudes in the German media, which depicted childless families in a negative light. However, we should take into account that this increase in ideal fertility is not consistent with findings from other German national, as well as international, surveys, and that in the Eurobarometer data-as we have already pointed out - the national sample sizes are quite low, with the consequence that results may be not very robust, especially when samples are broken down by sex and age. In particular, the proportion of actual childlessness in West Germany seems to be largely underestimated by the 2006 Eurobarometer data. This circumstance might have pushed up the values of ideal family size, given that the "no-child" ideal is an option most likely selected by childless people. ${ }^{5}$. In the inter-survey period the proportion of those childless decreased in West Germany (from 38 to 23\%), but in East Germany it even increased (from 21 to $30 \%$ ), while the ideal family size rose in both these regions. The variation in the share of childless women may not be the reason behind the increasing German ideals and additional factors should be found to comprehensively explain the unexpected German finding. Incidentally, in the case of East Germany it may be the new sample survey design that was partly responsible for the inconsistency, since the sample size in the 2006 round was only 500 people, against 1,000 in the previous wave of 2001. In agreement with the interpretation given above for the high ideals registered in West Germany, there were almost no changes in the intended number of children among women aged 25 to 39 years in West Germany between 2001 and 2006. The increase in the indicator of ultimately intended family size by around 0.3 children in 2006 as compared to 2001 was entirely due to the higher actual level of fertility recorded among the respondents in the 2006 survey, while the number of additionally intended children declined slightly.

\section{Ultimately intended number of children}

The ideal number of children, even though understood as a personal ideal, is different from the concrete childbearing careers that people plan. I therefore look at the "ultimately intended family size" instead, computed by summing up the number of children already born with those that people still intend to have in the future. The analysis of this fertility indicator confirms and strengthens the results shown for the ideals. In Figure 2-where the countries are ordered by the mean ultimately planned family size - a below-replacement family size appears as a desirable target for many people in Europe.

However, for our purpose the difference in actual childlessness between the 2001 and 2006 EB waves is more relevant than the actual level of underestimation of actual childlessness in 2006, because the increase in ideal family size is evidenced by a comparison of 2001 and 2006 EB data. 
Figure 2:

Mean ultimately intended family size, by country. Women aged 25-39

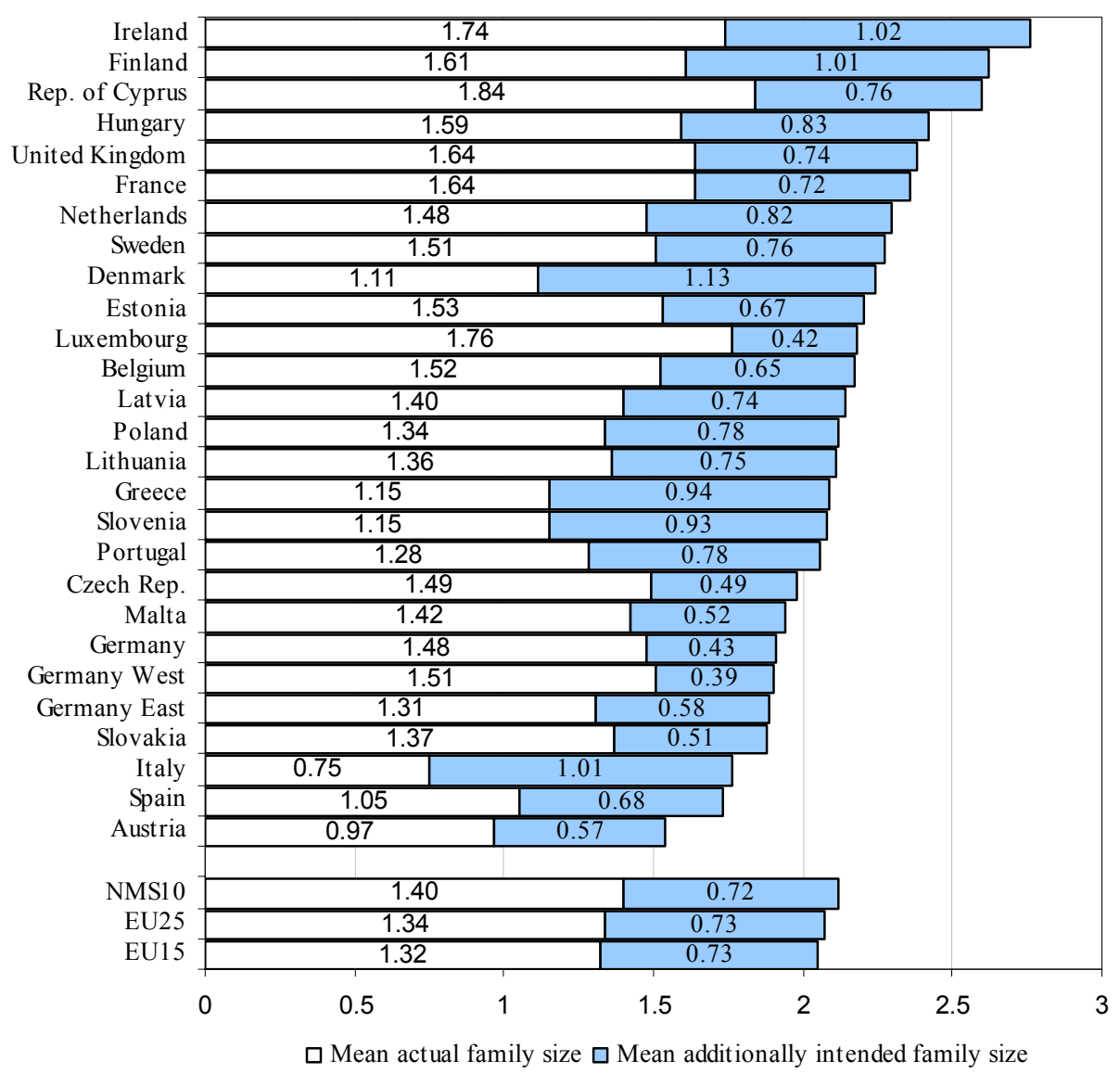

It may be argued that such low levels are due to the increasing diffusion of a childlessness preference. The contribution of childlessness to the low ultimately expected number of children may be better investigated by distinguishing between temporary and permanent childless women of childbearing ages (Figure 3). 
Figure 3:

Permanent and temporary childless women by country. Ages 25-39

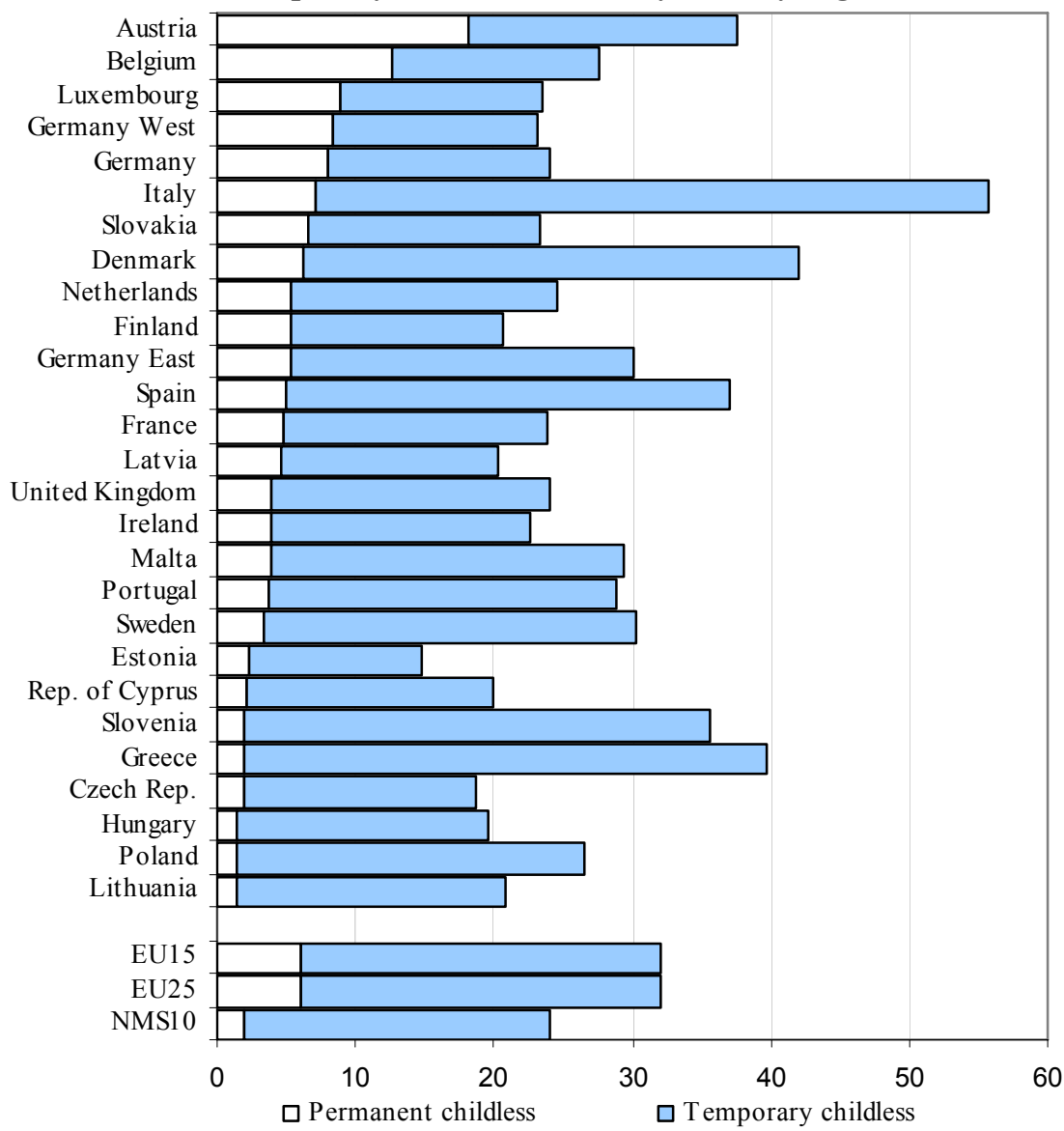

The first group relates to female respondents who are childless at the time of the interview but plan a child in the future, the latter group refers to women who are currently childless and do not intend to have a child in the future. ${ }^{6}$ The temporary childlessness - which has to do with the postponement of childbearing - is not irrelevant in many of the European countries, ranging from $15 \%$ in Estonia to $56 \%$ in Italy, but its impact on the ultimately expected family size is limited because it pushes downwards mainly the first addendum of such an indicator, i.e., the actual family size, and presumably it does so temporarily. ${ }^{7}$

6 Of course we are not able to see whether the intention not to have a child will be stable over time and we cannot exclude that these women will like to have children later on.

7 Women temporary childless also show a lower mean total ultimately intended number of children as compared to women with children. But some literature has shown (Miller and Pasta, 1995) that they may be very likely to revise upwards their initially intended family size once they get their first child. 
Permanent childlessness, which is supposed to be more stable over time and to have the strongest effect on the ultimately intended family size, is only a marginal phenomenon. Interestingly though, Austria is at the top rank among the EU-25 countries with $18 \%$ of current childless women opting for a no-child family. Comparable values are observed only in Belgium, $13 \%$, while in all the other European Union countries less than $10 \%$ of the current childless women report their condition as a permanent choice (Figure 3).

\section{Relationship between ideal timing and ideal quantum of fertility: a paradox?}

An interesting result evidenced by the analysis of the EB 2006 data is related to the ideal time to start childbearing. The issue is addressed in the questionnaire with the following questions: "In your opinion, what is the ideal age for a woman to have her first child?" and "In your opinion, what is the ideal age for a man to have his first child?", which were followed in the questionnaire by two questions on the limit age for becoming a parent: "And from what age should a woman no longer have children?" and "And from what age should a man no longer have children?"

First, I examine the ideal time to start a family in comparison with the observed age at the birth of first child; second I analyse the relationship between ideal timing and quantum.

The ideal age for becoming a parent is higher than the actual age at the transition to parenthood. This is generally true for women and men at each age, with the only exception of male respondents aged 40 or older who on average would have ideally liked to become a father half a year earlier than they actually did (Figure 4). If we focus on respondents of childbearing ages 25-39 years and select only those who have already started their reproductive career, the mean age at the first child among this group is 24.6 and 26.7 years for male and females, respectively. Respondents, either men or women, think that women should ideally become mothers half a year later than they actually do, at around 25 years. The ideal age to become a father almost corresponds to the actual one in the view of men, but women indicate that men should become fathers one year later than they actually do.

It may be assumed that modern lifestyle imposes on individuals a high competition between children and rivalling preferences (for job career, leisure and so on), but does not induce them to completely reject the idea of a family life with children. In contrast, most Europeans simply would prefer to start a family later in their life - a result that fits perfectly with the increasing childbearing postponement observed in Europe in the last few decades. 
Figure 4:

Mean ideal age to become a father or a mother. EU-25

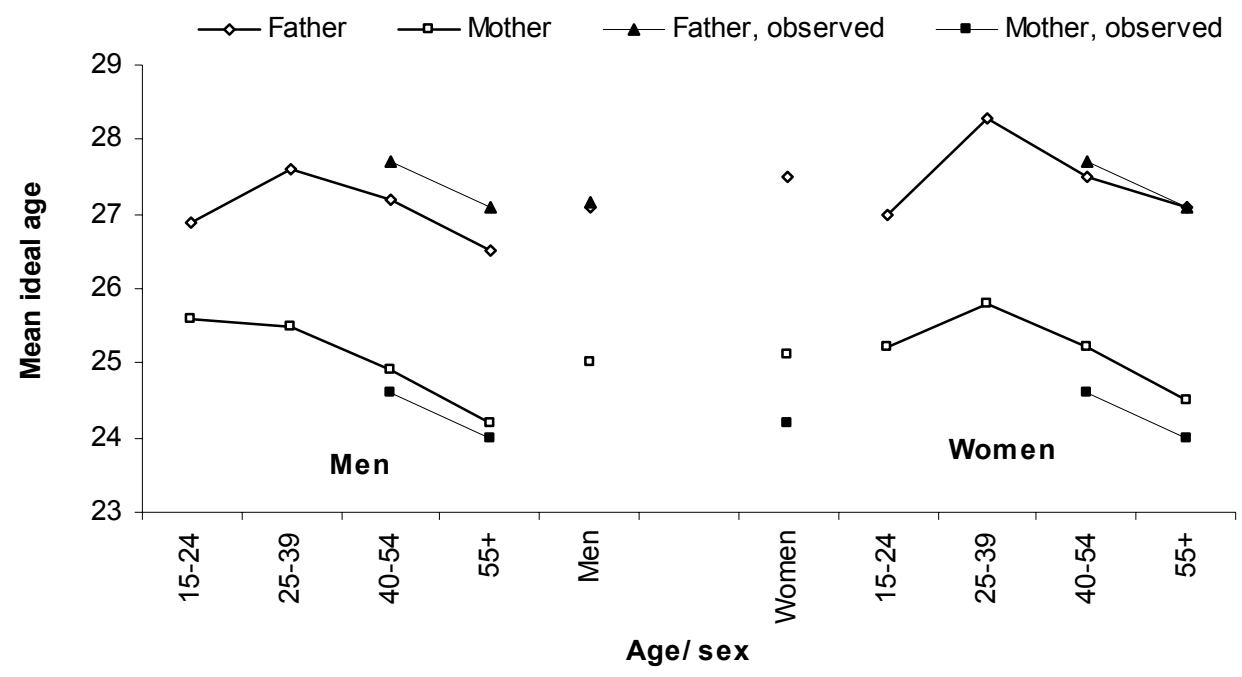

Moreover, while early childbearing does expose people to a higher risk of having a larger number of children, the ideal of building a family already at a young age is not necessarily associated with the preference for larger families. In contrast with actual fertility, the quantum of which is negatively associated with its tempo, countries with higher mean family size ideals show on average older ideal ages at the start of childbearing, even though the relationship is significant only at the 10\% level (Figure 5, A and B). This circumstance, together with the late age considered to be the limit age for motherhood by the young female respondents, i.e., 42 years, may make persistent postponement in the years to come very likely.

The implication of this finding is that the relationship between later childbearing and lower fertility might be weakened as long as having children at older ages is made possible to mothers, since the event as such seems to be largely accepted - and even considered as preferable-among the young generations.

From this perspective, assisted reproductive technologies could come in support of the individuals' conviction that childbearing is an event possible at relatively late ages, which in their perception lessens the biological limits to reproduction. 
Figure 5a:

Relationship between mean actual number of children and mean age at the birth of the first child. Women aged 40 to 65,25 EU countries

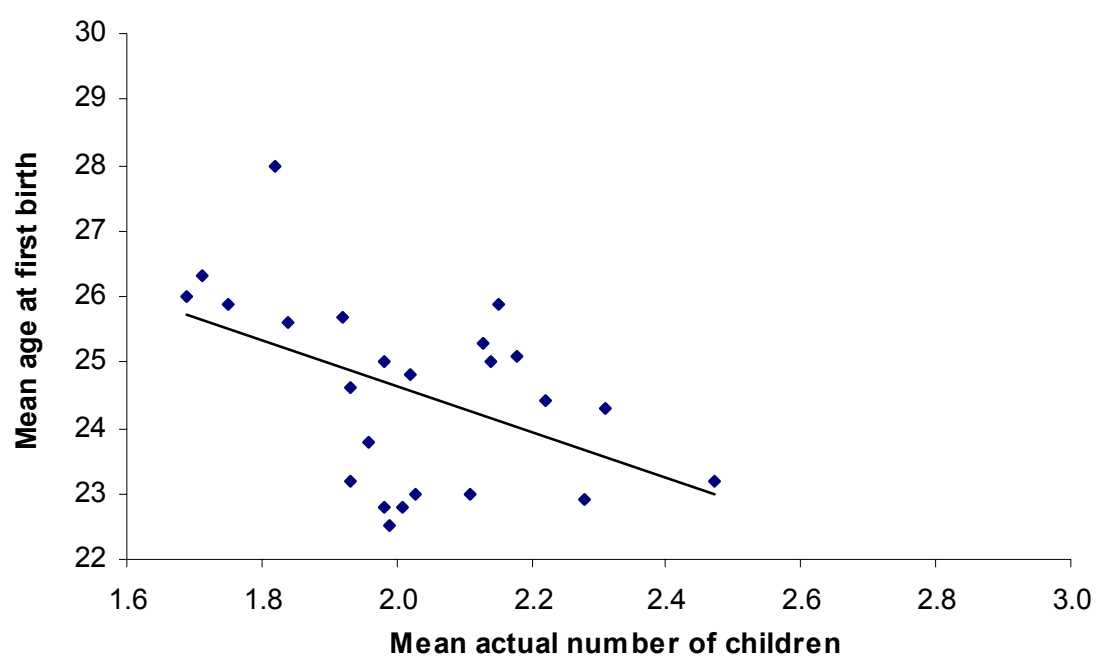

Figure 5b:

Relationship between mean ideal family size and mean ideal age at the first childbearing. Women aged 25 to 39.25 EU countries

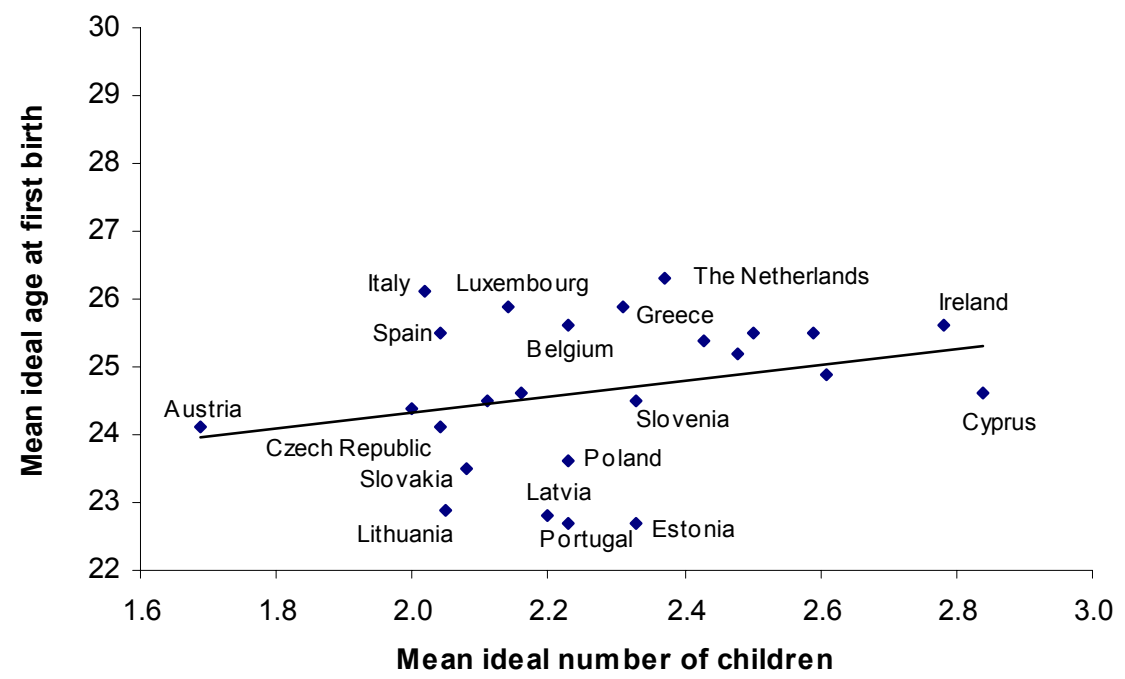

Note: Only some country labels are displayed in the graph on panel B, in order to let the graph be more readable. The correlation between the two variables is equal to -0.4 in panel $\mathrm{A}$ and to +0.3 in panel $\mathrm{B}$. Both are statistically significant at $10 \%$ level. In panel A Ireland appears as an outlier and is taken out from the analysis. 


\section{Relevant aspects in the childbearing decision and its outcome}

The circumstances considered essential for having children may be captured by two different questions included in the Eurobarometer 2006 questionnaire. One is more general, and addressed as follows: "According to you, how important is each of the following in the decision on whether or not to have a(nother) child?" Here respondents were required to indicate the importance of each circumstance listed in the questionnaire and read out by the interviewer, by choosing one of the four following categories: "very important", "fairly important", "not very important", "not at all important".

A second question is more personal and related to the reasons why the childbearing desires expressed at the beginning of the reproductive period were not realised in the subsequent years. The question reads as follows: "Have you had as many children as you wished to have when you were around 20? We are still talking about your biological children", and it comes immediately after a retrospective question asking: "Thinking back to the time when you were around 20 years old, how many children did you want to have at that point for the rest of your life? We are talking about your own biological children here."

\subsection{General circumstances in the childbearing decision}

The ten circumstances relevant in the childbearing decision that are explicitly listed in the response options of the EB questionnaire refer either to the health status of the couple, to economic conditions, i.e., financial situation, housing conditions, cost of children and the work situation of either or both partners, to institutional factors such as the opportunity to go on parental leave or the availability of child care provision, or to the presence of a supportive partner (see the questionnaire in Testa 2006 for the wording of the relative items). None of these conditions were considered unimportant by the respondents, while some of them-namely, the cost of children, the availability of child care provision, the opportunity to go on parental leave and the working situation of the mother-are indicated as not very important by around $10 \%$ of Europeans aged 15 to 39 (Figure 6).

The circumstances in the childbearing decision assessed to be most important by respondents in reproductive ages are: the mother's health condition, the presence of a supportive partner and the health status of the father, options considered as very important by $75 \%, 71 \%$ and $68 \%$ of interviewed individuals, respectively (Figure 6). 
Figure 6:

Relevance of several circumstances in the decision to have children. EU-25. People aged 15 to 39

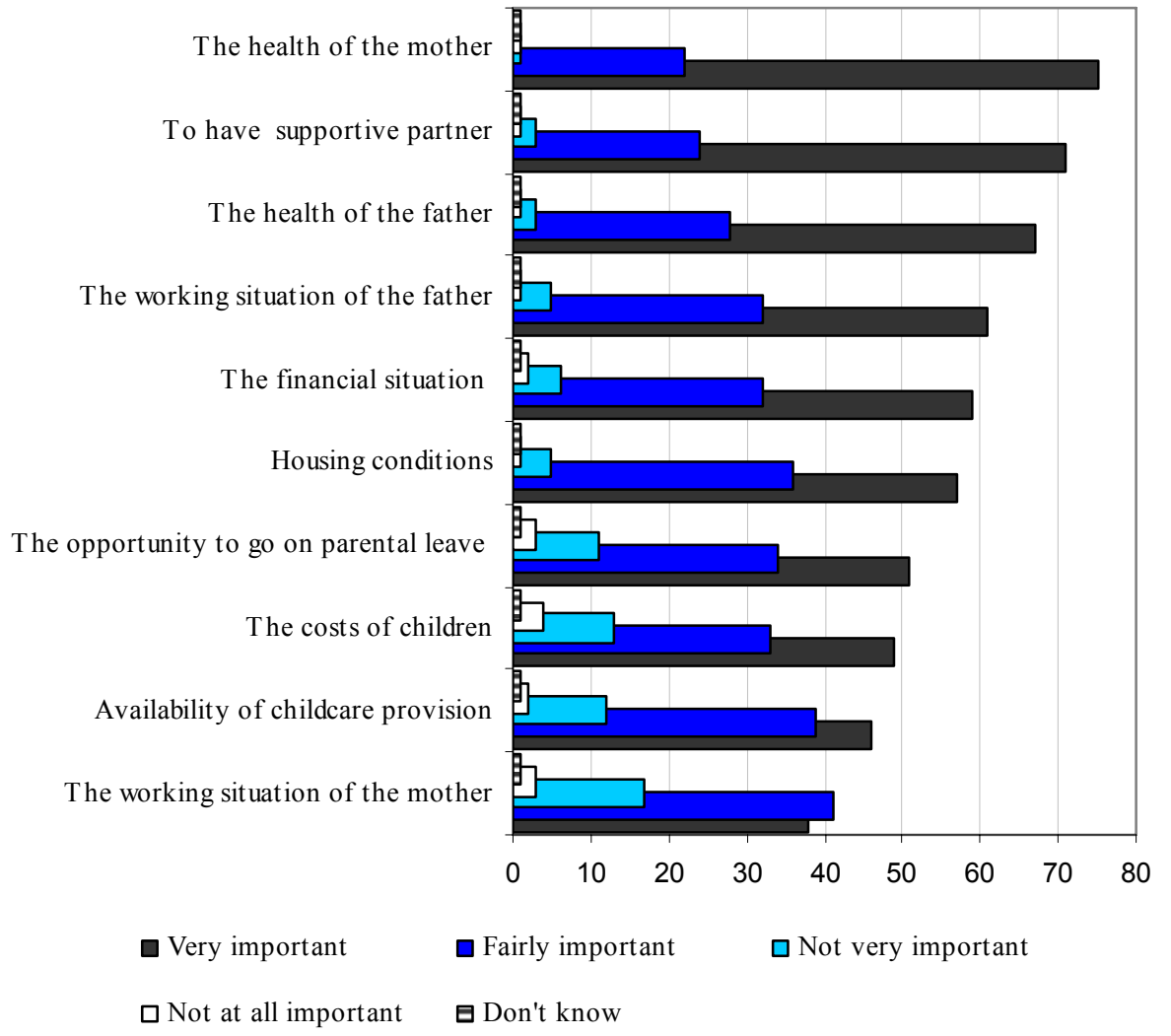

In Table 3, I focus only on the proportion of people assessing a given factor as 'very important' for having children by gender and parity, because this response option seems to better discriminate respondents and countries. As expected, the presence of a supportive partner is named as a relevant prerequisite for having children more often by those who already have children than by their still childless counterparts. Surprisingly, the couple's housing conditions and financial situation are more important to men and women without children as compared to those who have already started to build a family. It is also interesting to point out that a good health condition of the couple is a circumstance more often selected by those with children. This might be due to the presence of a selection effect, because those who have already a family are bound to have more positive attitudes towards childbearing as such and are therefore more likely to select factors that are out of their control. The availability of child care provision and the opportunity to go on parental leave are more relevant for women than to men: $55 \%$ of the women and $45 \%$ of the men attribute a high relevance to the first 
factor, while the same proportions are $47 \%$ and $42 \%$ concerning the possibility of benefiting from parental leave (Table 3 ). This finding has to be related with the role of mothers who are the main providers of child care and therefore more sensitive to the presence of child care structures and to the opportunity of taking a leave that could enable them to combine work and family activities more easily. Consistent with this view of the mother as the main responsible person for childrearing tasks, the mothers' working situation appears to be not all that relevant in the childbearing decisions of male respondents, for only $30 \%$ of them would take it into account while the same percentage is $45 \%$ and $40 \%$ among women without and with children, respectively.

Interestingly, there are no significant differences in the responses given by childless respondents and individuals with children. Factors that appear relevant to the group of those who already are parents are also considered relevant by those who have no children yet. Having already started the reproductive career does not change the opinion on the relevant circumstances for having children. We are not able to seen whether already having children changes the relative importance of each of these circumstances in respect to the others, i.e., the ranking of the listed conditions in the individuals' perception.

Table 3:

Circumstances very relevant in the decision to have children. EU-25. Respondents aged 15 to 39, by gender and parity (\%)

\begin{tabular}{lcccc}
\hline & \multicolumn{3}{c}{ Men } & \multicolumn{2}{c}{ Women } \\
\cline { 2 - 5 } & parity 0 & parity $1+$ & parity 0 & parity 1+ \\
\hline The health of the mother & 74 & 79 & 75 & 78 \\
To have a supportive partner & 71 & 75 & 72 & 73 \\
The health of the father & 68 & 69 & 65 & 68 \\
The working situation of the father & 62 & 62 & 61 & 61 \\
The financial situation & 61 & 56 & 62 & 58 \\
Housing conditions & 56 & 53 & 61 & 57 \\
The opportunity to go on parental leave & 45 & 47 & 56 & 55 \\
The costs of children & 48 & 48 & 52 & 51 \\
Availability of child care provision & 42 & 46 & 48 & 48 \\
The working situation of the mother & 34 & 33 & 45 & 40 \\
\hline
\end{tabular}

Note: The circumstances are ordered according to the importance given to them by the respondents, as in the previous graph. 


\subsection{Personal difficulties in the fulfilment of childbearing desires}

The analysis of the circumstances seen as preconditions for having children is complemented by an examination of the personal obstacles that impede individuals from meeting their fertility targets. This different approach may help to know the concrete factors that compete with the childbearing desire, but it has one main drawback: only the reasons for not having had as many children as desired may be individuated, because there are no questions in the EB questionnaire on the personal factors that make if more difficult or easier for respondents to have as many children as they wished.

In the EB 2006 survey a retrospective question asks respondents to remember their early childbearing plans, i.e., the plans that they had at age 20. In a subsequent item, respondents are invited to make a personal assessment of the consistency between their earlier fertility plans and their current actual family size $^{8}$. Only $27 \%$ of all individuals aged $25-39$ years did in fact meet their fertility desires, while the discrepancy is made up of $7 \%$ who have even larger families, $41 \%$ of individuals who achieved less children than they had wished, and $22 \%$ of respondents who have families smaller than initially desired but still intend to have children in the future (Table 4). Consistency is realised at an average family size of 1.9 children, while the mean size of families larger than those actually desired is clearly above replacement level, i.e., 2.6 children. The inconsistency originated by unplanned births seems to be driven by initial childbearing plans being particularly low, i.e., on average 1.3 children. A family size close to replacement level is preferred by respondents who have not yet managed or who are not managing to meet their targets, the average values being 2.0 and 2.2 children, respectively (Table 4). In particular among people who have definitively given up hope of ever meeting their fertility wishes, the main reasons reported for missing out on their child wish were related with the lack of a right partner $(16 \%$ of the responses), or the right time ( $15 \%$ of the answers), or with a change in their priorities (10\% of the cases) (Figure 7). The relatively high proportion of respondents who gave spontaneous answers (14\% of the total number of answers) induces us to assume that there may be other competing preferences that are not well captured by the items included in the questionnaire. Interestingly, women are reporting health problems more often than men (13\% and 5\% of answers among female and male respondents), while men express more often than women either uncertainty ( $10 \%$ of male versus $5 \%$ of female respondents), or a lack of the right

\footnotetext{
Of course this assessment is conditioned by the fact that respondents did in fact report a given desired family size. However, some of them did not give any numerical answers to this, because they either did not know how many children they would have liked at the age of 20, or simply did not care about the issue at that time, or did not know, options explicitly covered in the questionnaire. These respondents were excluded from the consistency analysis. They made up $27 \%$ and $16 \%$ of males and females, respectively, and they actually have, on average, 0.8 and 1.3 children, values not very far away from the overall means.
} 
time $(18 \% \text { and } 12 \% \text {, respectively })^{9}$ (Figure 7). This last option may be connected with postponement and, specifically, it may individuate the group of perpetual postponers, i.e., those who never find the right time for having a first child or for enlarging their family but repeatedly delay fertility and finally end up with a family smaller than originally intended. Change of priorities is an item that concerns people who have voluntarily adjusted downwards their desired number of children and thus does not reflect a real inconsistency but sends us back to investigating the motivations behind such an adjustment.

Interestingly, economic motivations such as housing difficulties and the high cost of children play only a minor role in the reasons why people missed their fertility targets: the first factor is mentioned in $4 \%$ and $3 \%$ of the male and female responses, respectively, and the second one accounts for $7 \%$ versus $8 \%$ of the total answers given by men and women (Figure 7).

In consistency with the role of women as main child care providers and with the previous findings on the main aspects of childbearing decisions, difficulties in combining work and families are more relevant to women than men, as this reason was mentioned in $10 \%$ and $6 \%$ of the female and male responses, respectively (Figure 7).

Table 4:

Consistency between childbearing desires at age 20 and subsequent fertility. People aged 25 to 39, EU-25

\begin{tabular}{|c|c|c|c|c|c|c|c|c|c|}
\hline & \multicolumn{3}{|c|}{$\begin{array}{c}\text { Proportion by } \\
\text { consistency category }\end{array}$} & \multicolumn{3}{|c|}{$\begin{array}{l}\text { Mean desired family } \\
\text { size }\end{array}$} & \multicolumn{3}{|c|}{$\begin{array}{c}\text { Mean actual family } \\
\text { size }\end{array}$} \\
\hline & Males & emales & All & Males & Females & All & Males & Females & All \\
\hline $\begin{array}{l}\text { I have as many } \\
\text { children as desired }\end{array}$ & 26 & 30 & 28 & 1.7 & 2.0 & 1.9 & 1.7 & 2.0 & 1.9 \\
\hline $\begin{array}{l}\text { I have more children } \\
\text { than those desired }\end{array}$ & 7 & 10 & 9 & 1.1 & 1.4 & 1.3 & 2.4 & 2.7 & 2.6 \\
\hline $\begin{array}{l}\text { I have less children } \\
\text { than those desired }\end{array}$ & 42 & 40 & 41 & 1.8 & 2.3 & 2.0 & 0.5 & 0.9 & 0.7 \\
\hline $\begin{array}{l}\text { Still intend to have } \\
\text { one or more children }\end{array}$ & 24 & 21 & 22 & 2.0 & 2.4 & 2.2 & 0.5 & 0.7 & 0.6 \\
\hline TOTAL & 100 & 100 & 100 & 1.7 & 2.1 & 1.9 & 0.9 & 1.3 & 1.2 \\
\hline Number of cases & 2365 & 2726 & 5091 & 2365 & 2726 & 5091 & 2365 & 2726 & 5091 \\
\hline
\end{tabular}

Moreover, a gender effect emerges if men's responses are analysed separately from those of women. Men are more prone to recognise health impediments of their partners than their own. Conversely, women are more often reporting personal health problems than health difficulties of their partners. This may be also due to the fact that reproduction is more constrained over time for women than for men. 
Figure 7:

Reasons for not having had as many children as desired at age 20 (in percent).

People aged 25- 39, EU-25

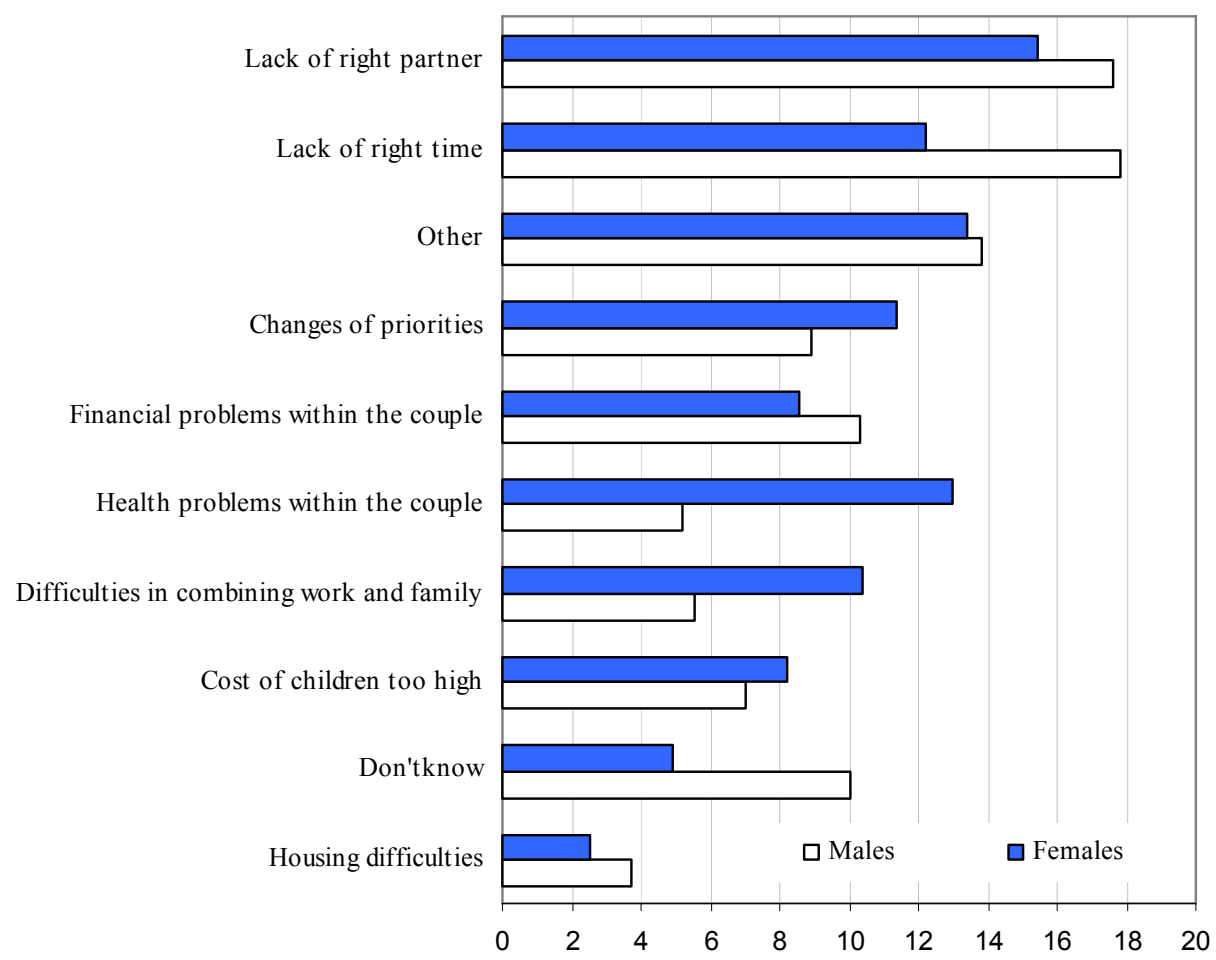

The two previous questions related to the fertility decision-making process are very different. The first one reflects the circumstances which are important in childbearing decisions, while the second one refers to the obstacles met by individuals in their personal life experience. The first question provides information on the factors that may induce people to have children, or prevent them from having any, while the second requires respondents to recall the negative factors that have prevented them from further childbearing and then caused a positive discrepancy between early fertility desires and subsequent reproductive behaviour ${ }^{10}$. Nevertheless, I found an interesting coherence between the answers given to these two items that may also strengthen the internal consistency of the data ${ }^{11}$. In particular, the presence of a partner who would

10 Unfortunately, as already pointed out in the paper, it is impossible to figure out the positive factors that allowed respondents to realise their desired family sizes in the EB data.

11 The analysis of the two questions is developed on different age groups: 15-39 years for the general circumstances and 25-39 years for the personal difficulties. This is because the questions on fertility desires and their realisation were asked only to individuals aged 25 years or older. 
provide some help in the household and/or with childrearing tasks is the most striking pre-condition to plan and have a family with children. The health status of the couple is in principle a relevant ingredient in the fertility decision-making process as well but does not emerge as one of the main obstacles for the fulfilment of earlier childbearing plans. Similarly, a good economic situation, mainly captured by the financial resources of the couple and the work status of the father, is a relatively important factor in the decision whether or not to have a child, but it is only a poor explanation for why people do not meet their previously desired family sizes. In the presence of a good partnership, postponement and changes in fertility intentions are the two most relevant factors explaining why Europeans are having smaller families than originally desired at the beginning of their reproductive career. This circumstance suggests a more in-depth investigation of the reasons for changing intentions, a direction of research recently taken by some demographers (Heiland et al. 2007; Testa 2007).

\section{Gender roles in family life and their link to the ideal family size}

The great relevance of a supportive partner in childbearing decisions and their outcomes prompts me to conclude this review of findings based on the EB 2006 with an analysis of what Europeans think gender roles in family life should be like.

At the end of the section reserved to fertility items, the Eurobarometer questionnaire includes a general question about men and women's roles in childrearing activities. The question is phrased as follows: "Here is a list of statements relating to the role of men and women when it comes to raising children. Please tell me to what extent you agree or disagree with each of them". Some of these statements - which may be found in the appendix - reflect a more traditional view, while others are closer to more liberal attitudes.

It is quite a contradictory result that emerges from the analysis of this item. There is almost a universal consensus among Europeans on the fact that both men and women should contribute to the household income or, if one prefers, a strong disagreement with the traditional model based on the male as main breadwinner. At the same time, however, mothers are supposed to take the most important part in the childbearing and rearing activities, and their presence in the labour market may compromise the happiness of the children and a good family life: around $50 \%$ of respondents think that a pre-school age child is more likely to suffer if his/her mother works and that family life on the whole would suffer when the woman has a full-time job (Figure 8). These findings support those coming from other questions of the EB survey-i.e., that mothers are the main child care providers and consequently may experience a conflict between their family and the working life, because on the one hand they are required to contribute to the 
household resources but on the other, their work outside the family is still seen as a potential damage to their children. I assume that in countries where this conflict is perceived more strongly, women are bound to prefer smaller families, because they feel their family tasks as a threat for their working career or, conversely, they perceive that their working career would keep them from being a good mother. This hypothesis seems to be confirmed by the EB 2006 data where I found a strong positive association between the mean ideal family size among young European women and the proportions of young respondents, aged 25-39, who are in favour of equal division of family tasks within the couple in the 25 European countries: countries which are more liberal in terms of gender roles also show higher family size ideals. The relative correlation coefficient is equal to 0.42 and significant at the 5\% level (Figure 9). One could argue that the relationship is caused by the link between gender roles and actual fertility and particularly by the impact of the first on the second one, but I found almost no correlation between these two last variables. In the correlation analysis, the respondents' views on gender roles are represented by a dummy variable which is equal to 1 if individuals agreed, totally or partially, with the three following statements: both men and women should contribute to the household income; a working mother can establish a just as warm a relationship with her children as a mother who stays at home; family life suffers when men concentrate too much on their work, and at the same time disagreed with the following statements: ideally, the woman should stay at home to look after the children while the man goes out to work; on the whole; family life suffers when the woman has a full-time job; a pre-school child is more likely to suffer if his/her mother works. The dichotomous variable used to connote respondents as having a traditional or a more liberal gender view is computed in quite a restrictive way, the reason being that I tried to capture with it the most extreme positions in the hypothetical continuum that goes from the most conservative to the most egalitarian set of views on gender roles. Indeed many respondents, while expressing their agreement towards egalitarian gender roles and saying that both men and women should contribute to the household income, also showed some reluctance towards mothers with a full-time job by stating that a pre-school child was more likely to suffer if his ther mother worked.

This finding suggests that preferences in childbearing may be driven by the level at which the roles of mother and working woman are competing with each other. 
Figure 8:

Respondents by level of agreement with several statements related to gender roles in family life. People aged 15 to 39

Both men and women should contribute to the household income

A working mother can establish a just as warm a relationship with her children as a non working

$$
\text { mother }
$$

Family life suffers when men concentrate too much on their work

All in all family life suffers when the woman has a full time job

A pre-school child is more likely to suffer if his/her mother works

Ideally, the woman should stay at home to look after the children while the man goes out to work

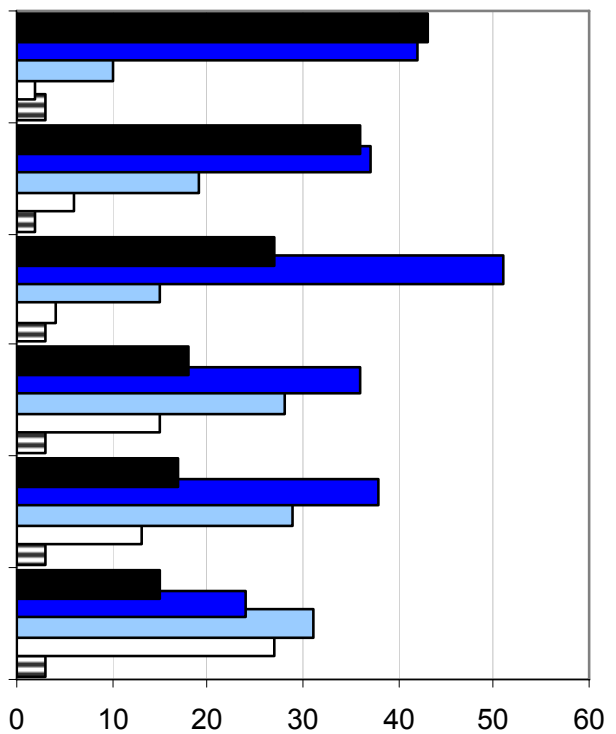

$\square$ Don't know $\square$ totally disagree $\square$ tend to disagree $\square$ tend to agree $\square$ totally agree Note: Statements arranged according to the proportion of respondents who totally agree with each of them.

\section{Figure 9:}

Relationship between gender roles in family life and mean ideal family size. Women aged 25-39, $25 \mathrm{EU}$ countries

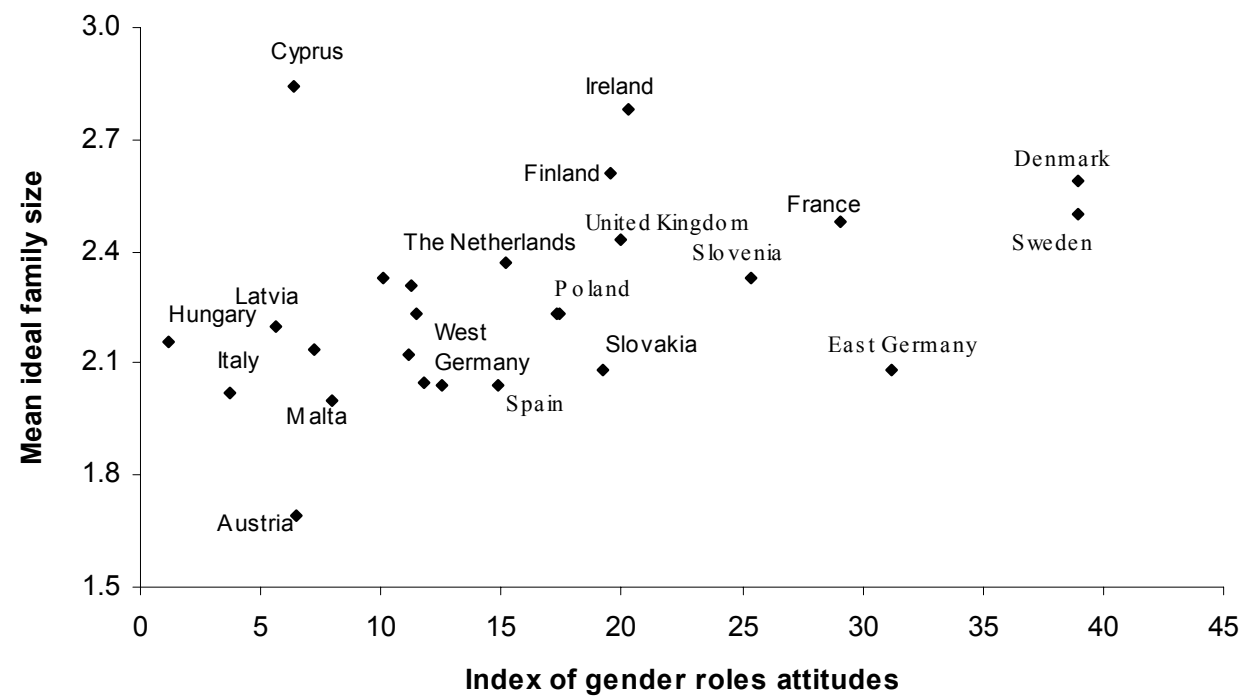

Note: Only some country labels are displayed in the graph, in order to let the graph be more readable. 


\section{Some concluding remarks}

The emergence of below-replacement family size ideals in Europe is confirmed by the EB 2006 data, even though we cannot detect any decline in the fertility ideals through the comparison with the previous EB round, carried out in 2001.

The presence of a low-fertility culture appears more consolidated if one looks at the widespread intentions for a family with less than 2 children. Indeed, in this case, it is not only in Austria that young people show such below-replacement levels, but in Germany, Italy, Spain, Slovakia, the Czech Republic and Malta as well. This could be read as a first sign that below-replacement fertility preferences may become more common also in other European countries in the future. In favour of this interpretation I found that young Europeans who are satisfied with their family size have, on average, a family with 1.9 children.

Similar to the ideal quantum of fertility, the ideal time for becoming a mother is higher than the actual age at first childbearing; in contrast to the actual tempo and quantum, however, the relationship between the ideal quantum and the ideal timing is positive: countries with a higher mean ideal age for motherhood also show larger ideal family sizes. On the basis of this finding, we may expect a further increase in actual fertility at older ages in the coming decades, as far as it will be made possible by the techniques such as Assisted Reproductive Technologies.

Having children is predominantly seen as an event that is conditioned to the presence of a partnership where both members are willing to be involved in the childrearing and family tasks. A supportive partner is one of the most relevant factors shaping women's fertility decisions and the lack of a right partner for raising children is the most frequently reported reason for failure in the fulfilment of earlier childbearing desires. Good health conditions are also an important precondition in the reproductive decision-making process but they become less relevant in justifying why people do not succeed in meeting their fertility aims, probably because fertility impairments concern only a limited and selected subsample of individuals. Beyond the non-existence of a partnership, postponement and changes of priorities are the most important factors competing with fertility preferences. In consistence with the relevant influence of a good partner on reproductive decisions, family size ideals are higher in those countries where the majority of people agree with the fact that men and women should equally share their responsibilities in childrearing tasks and family chores. This positive association between egalitarian gender roles and fertility ideals is also highly statistically significant. The finding suggests that fertility and childbearing intentions are influenced not only by actual difficulties in combining work and family, but also by the extent to which being a mother and having a working career is perceived as being in conflict with each other-on the one hand by the women themselves, and on the other, by the broader society they live in. 
The main caveat related to the analyses performed in the paper is the weak robustness of the Eurobarometer survey data on which it is based. Indeed, the country sample sizes are relatively small, around 1,000 people aged 15 and above for each country, and even smaller in some cases, namely Luxembourg, Malta, Republic of Cyprus and East Germany, with a sample size of only 500 individuals. This could be the reason behind some surprising results, such as the increase of family size ideals in Germany. Other international surveys, and particularly those planned within the Gender and Generation Surveys Program, will certainly allow more robust cross-national analyses on similar topics, providing also a tool for checking the external consistency of the Eurobarometer data. However, we are confident that central message given in this study is correct. Indeed, the main scope of the current work was to show some general trends in childbearing preferences and family size issues in Europe, as represented by the EU-25 as a whole, and the cross-national comparisons were only used to supplement the main aggregate results and to steer the discussion.

\section{References}

Fahey, T., and Z. Spéder. 2004. Fertility and family issues in an enlarged Europe. European Foundation for the Improvement of Living and Working Conditions.

Goldstein, J., Lutz W., and M.R. Testa. 2003. The emergence of sub-replacement family size ideals in Europe. Population Research and Policy Review 22(1-2): 479-496.

Heiland, F., A. Prskawetz, and W.C. Sanderson. 2007. Are individuals' desired family sizes stable? Evidence from West German panel data. European Journal of Population. Forthcoming.

Miller, W.B., and Pasta D.J. 1995. How does childbearing affect fertility motivations and desires? Social Biology, 42: 185-198.

Testa, M.R. 2002. Attitudes of European towards fertility: ideals, desires, intentions and realizations. Eurobarometer 56.2 - European Commission.

Testa, M.R. 2006. Childbearing preferences and family issues in Europe. Special Eurobarometer 253/Wave 65.1 - TNS Opinion \& Social, European Commission, available at: http://www.oeaw.ac.at/vid/download/ReportESEMPLAgeingandFertility 20061027.pdf.

Testa, M.R. 2007. Changes in child-number desires after the birth of a child. Unpublished manuscript.

Testa, M.R., and L. Grilli. 2006. The influence of childbearing regional contexts on ideal family size in Europe. Population, 61(1-2): 109-138.

Toulemon, L. 2003. La fécondité en France depuis 25 ans. Haut Conseil de la population et de la famille. Secrétariat général: Direction de la population et des migrations. 